\title{
Job Quality and Well-Being: Evidence from DR Congo
}

\author{
Christian Kamenga Mapurita1*, Jody Ngongo², Dickens Liwono Moba², Gabriel Mbuyi² \\ ${ }^{1}$ CREAM-Université de Rouen Normandie et Université Nouveaux Horizons, Lubumbashi, DR Congo \\ ${ }^{2}$ University of Kinshasa, Kinshasa, DR Congo \\ Email: *christian.kamenga@univ-rouen.fr, *christian.kamenga@unhorizons.org, jodyngongo@yahoo.com, \\ dickens645@gmail.com, gabriel.mbuyi@vodacom.cd
}

How to cite this paper: Kamenga Mapurita, C., Ngongo, J., Liwono Moba, D., \& Mbuyi, G. (2021). Job Quality and WellBeing: Evidence from DR Congo. Theoretical Economics Letters, 11, 978-994.

https://doi.org/10.4236/tel.2021.115062

Received: June 12, 2021

Accepted: October 23, 2021

Published: October 26, 2021

Copyright $\odot 2021$ by author(s) and Scientific Research Publishing Inc. This work is licensed under the Creative Commons Attribution International License (CC BY 4.0).

http://creativecommons.org/licenses/by/4.0/

\begin{abstract}
In the context of dualism of the labor market-informal sector labor market and formal sector labor market-this study assessed the impact of job quality on worker's well-being. Using the first stage of the 2012 national survey data 1-2-3, preliminary results revealed that among 1443 employees, $85.44 \%$ were working in the informal sector whereas $14.56 \%$ in the formal sector. Given its multidimensional characteristics, the job quality was measured by six components such as job security, existence of union, training, employer's support, working hours and promotion. In terms of contribution of each dimension, the Multiple Component Analysis was applied and based on the finding, we have selected the first three components with $46 \%, 39 \%$ and $15 \%$ respectively as a contribution to the construction of the job quality index. On the other hand, the well-being was measured by worker's income and two classespoor employee and non-poor employees-were created using the 2012 monetary threshold according to the place of residence. We estimated afterwards the logit model. Our results have revealed that the effect of job quality was significantly positive on worker's well-being in both cases workers from Informal Sector and all workers irrespectively of their sector. In formal sector, the evidence of the significant impact of job quality was statistically rejected. The main explanation of this finding can be imputed to the job quality level which was already high in formal sector compared to informal sector. Furthermore, for all workers, this result was a consequence of the dominant effect of job quality on worker's well-being in informal sector on that in formal sector. In view of above findings, there is a need of controlling and strengthening the job quality in informal sector for an increase in job security index by one unit, the probability that worker's well-being increases is 0.38 .
\end{abstract}

\section{Keywords}

Job Quality, Welfare, Multidimensional Index, Logit Model 


\section{Introduction}

The worker's welfare is one of the most important drivers of productivity in work. To ensure the growth of firm, the manager has the interest to unlock the potential of his employees through their full participation in tasks they are constantly devoted to performing. Since Aristotle's works, it is well known that well-being is an overarching goal of all human actions (Kabote, 2017: p. 28). Within the capitalism scheme, the overexploitation of working class has cleary demonstrated its limit through the capitalism crisis. When the manager does not pay attention to the well-being of workers, it is not surprising that he/she repeatedly records conflict in workplace. As a result, the firm would experiment strike, high absenteeism rate, lower working hours, insatisfaction, and more importantly, fall in productivity. Recently, the public policy in developed country has focused their discussions on decent work-defined by ILO as the sum of people's aspirations for opportunity and income; rights, voice and recognition; family stability and personal development; and fairness and gender equality (Pereira et al., 2019: p. 1). This debate remains out of the Africa policy agenda in general and specifically, in DR Congo.

The welfare can be significantly impacted if work is fulfilling, providing much more than the means to live (Warhurst et al., 2017: p. 6). In terms of redistribution, the benefit seems to be widely inequitable depending on labour market segment-informal job or formal job. In general terms, the well-being is measured as of outcomes achieved in the two broad domains: material living conditions (income and wealth, jobs and earnings, housing conditions) and quality of life (health status, work-life balance, education and skills, social connections, civic engagement and governance, environmental quality, personal security and subjective well-being) (OECD, 2013: p. 21). According to the objective view, the income is one of the main measure of the well-being (Western \& Tomaszewski, 2016: p. 8).

The job quality refers to the extent to which a set of job attributes contributes to workers' well-being to improve or worsen it (Muñoz de Bustillo et al., 2011) ${ }^{1}$. Based on that point of view, it is undoubted that this concept is fundamentally multidimensional.

Warhurst et al. (2017: p. 14) have identified two main approaches addressing the relationship between well-being and work: well-being from work (Bryson et al., 2012; Pharr et al., 2012; Wanberg, 2012; Nichols et al., 2013) and well-being in work (Grunberg et al., 2008; Osei-Bonsu, 2014; Chen \& Hou, 2018).

On the opposite to the second approach which was concerned with the socialpsychological effects of not being in work through unemployment, the first one put a high emphasis on the effect of changes to work on employees. The detailed discussions on the second approach are beyond the scope of this study.

Studies that assessed impact of job quality on well-being are abundant in ad${ }^{1}$ Quoted by Moroc \& Bărnuțiu (2019: pp. 54-55). 
vanced countries (Bryson et al., 2012; Sivapragasam and Raya, 2014; Guzi \& de Pedraza García, 2015; Ariza-Montes et al., 2018; Esenaliev \& Ferguson, 2019) but little attention was given to the developing countries except for Mafini and Dlodlo's work papers as well as Mafini's (2014). However, the role of informality in labour market segment is neglected when examining the link between job quality and welfare in studies conducting in Africa. Thus, this research seeks for fulfilling this gap. The focus on the segmentation of labour market in measuring the impact of job quality on welfare is our main contribution. However, the study was not able to address selection and causality issues adequately as it only used one wave of the survey. Those issues can successfully be handled with the panel data i.e. the same individuals or households are repeatedly observed over the time. Unfortunately, the two waves of the national surveys of the DR Congo (2005 and 2012) did not cover the same individuals or households. The aforementioned problem is part of the limit of this study.

The main question that this paper attempts to address is the following: how does job quality in both formal and informal labour market affect employee's well-being?

The main concern of our paper is strongly connected to the segmentation theory; "its basic argument is that instead of a single labour market functioning according to competitive rules of supply and demand, there are different segments which function with different rules"2 (Muñoz de Bustillo et al., 2011: p. 55).

Instead of segmentation, we prefer to employ dualism as Doeringer and Piore (1970) where primary sector opposed to "the secondary sector" offers good job, with high wages, secure employment and good prospects of career advancement. The secondary sector contains the bad jobs, with low wages and poor working conditions. In our context, dualism is referring to informal labour market and formal labour market.

The remainder of the paper is organizing as follows: the Section II gets a closer look upon the review of literature and the Section III deals with methodology and data. In the Section IV and Section V, we present the results and draw some concluding remarks respectively.

\section{Review of Literature}

Nowadays, there is an increasingly much interest in empirical studies focusing on the link between Job quality and well-being. In line with this issue, Sivapragasam and Raya (2014) conducted in India a pilot study involving a randomly selected sample size of 240 professionals working in IT Parks. They employed first and foremost various techniques to assess the psychometric properties such as internal consistency and construct validity and the results were found adequate.

${ }^{2}$ The competitive form is only one mode of labour market organization, coexisting along other modes of organization. 
Measuring the job quality by the job demographic variables-like the income level of the professionals, average working hours, total work experience, company type, sub-category and size-and well-being by WHO well-being index, they found using the Principal Component Analysis that the good job quality was related to high well-being and the poor job quality was also related to poor well-being. Furthermore, the model of Structural Equations suggests that the Employee well-being played a significant mediation effect between the job quality and the outcomes variables such as perceived efficacy and engaged employee.

In their paper entitled "A web survey analysis of subjective well-being”, Guzi \& de Pedraza García (2015) also explored the relationship between quality of work-such as type of contract, supervisory position, union membership, job qualification, working time schedule, work commuting, on-the-job search, job security and employment prospects-and subjective well-being (SWB) such as life satisfaction, job satisfaction and satisfaction with work-life balance. They used the Wage Indicator sample which counts 20,095 individuals aged from 15 to 64 years surveyed between 2005 and 2011. Based on that, the dependent variable (SWB) is an ordinal response variable, the authors estimated the ordered logit model with various explanatory variables including the quality of work.

As a result, they found the negative correlation between permanent contracts and job satisfaction, holding a supervisory position with no association with life satisfaction, but a positive effect on job satisfaction; union affiliation has a positive effect (referring to the importance of civic engagement ) on life satisfaction and a negative effect on job dissatisfaction; the over-qualification influence negatively the worker's life and job satisfaction but positively the work-life balance; working more than 40 hours a week or having an irregular working schedule both display a negative association with all three well-being domains. In addition, their results showed that workers employed in jobs with less security, were less satisfied in all three satisfaction domains. Similarly, individuals who were looking for another job while they had a job indicated disappointment with their current employment situation, and this also corresponded to lower SWB levels in all domains. In contrast, good career development opportunities in one's current place of work had a positive effect.

Using the 2010 Health Survey for England, Bryson et al. (2012) examined the link between the well-being, health and work. As a measure of well-being, they used the Warwick-Edinburgh Mental Well-being Scale (WEMWBS) including psychological functioning, cognitive-evaluative dimensions and affective-emotional aspects of well-being. As for work, they were interested in the characteristics of jobs among those in paid employment which cover four dimensions with high, medium and low categories: autonomy, support, security and control. Regarding the health, they used the 12-item General Health Questionnaire (GHQ12). We reported here only the results between the well-being and the work (job quality). Given the nature of outcome (WEMWBS) which is a continous variable, the linear regression was applied. Having controlled for age and region, it draws from their results that each of these four dimensions of job quality was independently 
associated with employee well-being and that, taken together, they accounted for around one fifth of the well-being of employees as measured on the WEMWBS scale. Employee well-being rose with greater autonomy, support, security and control among both women and men.

By selecting 15 countries that formed the EU-15 after incorporation of Austria, Finland and Sweden in 1995 from the European Working Conditions Survey (EWCS), Ariza-Montes et al. (2018) also explored the link between job quality and well-being as one of the three objectives of their paper. To do so, the sample was segmented into two subsamples at different times, 2015 and 2010: 7867 workers (5548 in 2010) from the five Piigs countries (36.2\%) and 13,894 (16,876 in 2010) from the 10 Farmers countries (63.8\%). The World Health Organization's Well-Being Index (WHO-5 items) is the dependent variable and the explanatory variables are the different dimensions of the Job Quality Index (JQI) such as: physical environment, work intensity, working time quality, social environment, skills and discretion, prospects and finally, earnings. Having controlling the demographic variables (male, education, age), they estimated three different linear model with OLS technique: 1) Farmers model, following by; 2) the Piigs model, and finally; 3) Both the Piigs/Farmers model. In the case of Farmers workers, these authors mentioned that the influence of job quality dimensions seems wider and clearer, since up to five of the seven indicators showed statistically significant results. On the one hand, as with the Piigs model, the well-being of Farmers workers was influenced by a good social environment (in a positive sense) and, on the other, by the skill and discretion index (in a negative sense). Finally, they noted that the job quality indices that defined the well-being of this common model were the social environment and the expectations of professional career (in a positive sense), and the working time quality and the skill and discretion index (in a negative sense).

Like the previous studies, Esenaliev and Ferguson (2019) assessed the impact of job quality on well-being in Kyrgyzstan. From the fourth wave of the Life in Kyrgyzstan Survey (LiK), they generated a sample of 2469 individuals who were engaged in work for monetary remuneration, either self-employed or as wage workers. In addition to the Clark's $(2005,2010)$ works who built five components of job quality (income; hours worked; job security; interestingness of work; and autonomy), they included job formality proxied by the presence of a written contract or "workbook" for wageworkers and by whether or not their business was registered with the Kyrgyz government for the self-employed. To measure the well-being, they used the subjective measure capturing the individual self reported well-being. Combining the Ordinary Least Square and the ordered probit regression, they found no significant relationship between the sub-indices (income and hours worked) and self-reported wellbeing. For the full indices, they found a positive and significant relationship such that higher job quality was associated with greater subjective wellbeing. The authors concluded that their findings fit with the job-demands-control model, whilst suggesting that reward based models were insufficient to describe the relationship between 
work and welfare in Kyrgyzstan.

For Africa cases, most of studies in this area were conducted in South Africa and there is no yet related research in DR Congo to our best knowledge. Considering the South Africa studies for example, Mafini (2014) examined the relationship between the job satisfaction-measured by six components, namely, workplace flexibility, skills utilisation, teamwork, remuneration and autonomy-and the Life satisfaction as the cognitive element of the well-being. To collect his data, the author administered a three-section questionnaire to 192 logistics practitioners in a South African steel-making company which were purposively selected. Using the Principal Component Analysis and the non-parametric correlation analysis, his findings outlined, on one hand, the positive significant relationship between the life satisfaction and the two dimensions of job satisfaction, namely, skills utilization and remuneration. And on the other hand, the weak positive relationship was found between the life satisfaction and the three remaining dimension such as workplace flexibility, teamwork and autonomy. As for contribution, mean score rankings showed that among the job satisfaction factors, skills utilisation was more important to logistics practitioners and autonomy the less important.

In the same line, Mafini and Dlodlo (2014) explored the relationship between extrinsic motivation, job satisfaction and life satisfaction amongst employees in a public organisation. They conducted a survey to 246 employees in a South African public organisation through a questionnaire. Using the same methodology with a little bit different than the previous research, except promotion ${ }^{3}$ which was significantly related to life satisfaction and not to job satisfaction; the evidence of the significant relationship between job satisfaction and the four components of extrinsic motivation-remuneration, quality of work life, supervision and teamwork-was not statistically rejected. With respect to managerial implications, the authors advance that optimising the aforementioned extrinsic motivation factors could lead to a reduction in dysfunctional actions by public employees, such as absenteeism, high turnover, industrial action and unsatisfactory work performance.

The existence of segmentation in labour market within African literature measuring the impact of job quality on welfare has not received attention yet. We analyzed in the current paper the impact of the job quality with regard to labour market segment-informal and formal-on the employee's well-being. Given the lack of information on the employee's subjective well-being in our data set, we used the worker's income as the measure of objective well-being. Taking into account the dualism of the labour market is our main contribution to the literature on this area. In addition, we computed the weight to construct the job security index, one of the job quality components, from each of its dimension through the Multiple Correspondence Analysis. In doing so, we differ from previous studies like Cassar (2010) who constructed a dichotomic variable to separate employee with full job protection from those in lack of protection.

${ }^{3}$ One of the job satisfaction dimensions. 


\section{Data and Methodology}

In this research, we used the 2012 national survey data from the National Institute of Stastics which is entitled "survey 1-2-3". As the name indicated, the survey was organised in three stages: the first one covered the employment, the second, the informal sector and the third one the household consumption. The sample size was 21,454 households with the response rate of $98.2 \%$. More precisely, we were limited to the data from the first stage that reports information on 111,679 individuals of which 1443 were employed.

Based on the above studies in literature and the data set we do have, the following dimensions refer to the job quality:

1) Promotion: Dummy variable which takes the value of 1 whether the employee is promoted and 0 otherwise.

2) Training: Like the previous, another dummy variable which takes the value of 1 if the employee gains any training supported by his or her employer and 0 otherwise.

3) Worked hours: A constructed dummy variable which takes the value of 1 whether the employee works more than $45 \mathrm{~h}$ and 0 otherwise.

4) Existence of union: A dummy variable which takes the value of 1 whether there is an union in firm where the employee works and 0 otherwise.

5) Job protection: The formal arrangements which characterize an economic activity with the aim of protecting workers against negative shocks related to employment (Lugo, 2007) ${ }^{4}$. Following Cassar (2010), the dimensions of job protection are referring to:

- Signed work contract: dichotomic variable which takes the value of 1 if the employee signs contract and 0 otherwise;

- Contractual relation: defining by a work contract status, either permanent (value equals to 1 ) or temporary (value equals to 0 );

- Paid maternity leave (hold for both men and women): it refers to whether the employee is entitled to pay maternity leave (value equals to 1 ) or not (value equal to 0 );

- Paid holidays: it refers to whether the employee is entitled to pay holiday (value equals to 1 ) or not (value equal to 0 );

- Paid sick: it refers to whether the employee is entitled to pay sick (value equals to 1 ) or not (value equal to 0 );

- Retirement pension: it refers to whether the employee contribute to the social security (value equals to 1 ) or not (value equals to 0 );

- Union membership: it refers to whether the employee belongs to the union (value equals to 1 ) or not (value equals to 0 ). We add this attribute here because there are some employees who are not member of union even though it does exist and consequently it is reasonable to consider them less professionaly protected.

Unlike Cassar (2010) who constructed a dummy indicator which equals to 1 ${ }^{4}$ Quoted by Cassar (2010: p. 5). 
whether the employee has a full job protection and 0 otherwise, we used the Multiple Correspondance Analysis to construct the job protection indicator. This approach has an advantage to compute the weights of each dimension.

6) Employer's support: Refers to whether an employee gets the support-in terms of transport and house allowance-from his or her employee. This is the new variable that we add among the job quality dimensions.

In order to avoid redundancy, we did not take into account remuneration among the job quality dimensions given the fact that the worker's income was capturing here the well-being. We created, afterwards, two classes distinguishing poor workers from non-poor workers. Furthermore, we do not also include the job informality which is used as a segmentation variable to disentangle the effect of job quality on employees working in formal labour market from those working in informal labour market.

As for methodology, logit model was used with various explanatory variables including the job quality based on that the dependent variable (objective well-being) is a binary response variable. The scheme of our study can be summarized as follows (Figure 1).

From that scheme (conceptual model), we derive the following econometric model:

$$
\mathrm{OWB}=a_{0}+a_{1} \mathrm{Pr}+a_{2} \mathrm{Tr}+a_{3} \mathrm{Wh}+a_{4} \mathrm{Eu}+a_{5} \mathrm{Jb}+a_{6} \mathrm{Es}+\mu
$$

With: $\mathrm{OWB}^{5}$ : Objective well-being $=\left\{\begin{array}{l}0 \text { if the employee is poor } \\ 1 \text { if the employee is rich }\end{array}\right.$

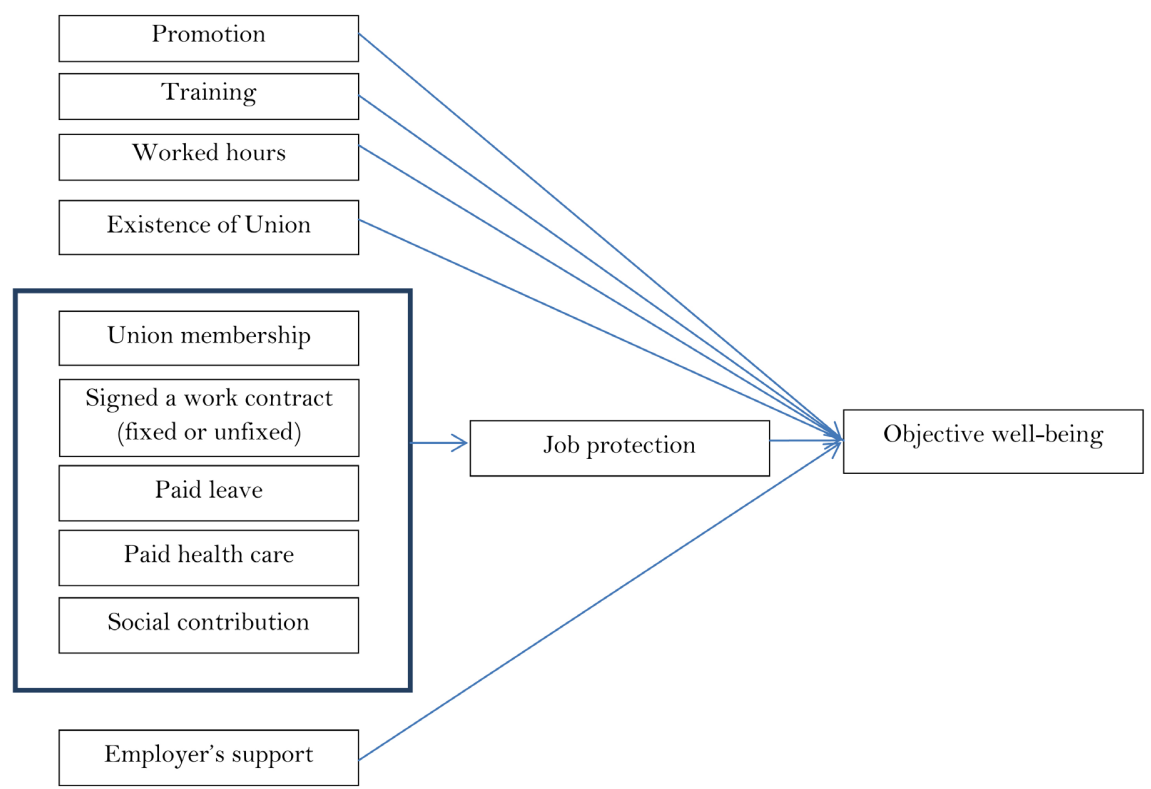

Figure 1. Relation between job quality and well-being. Source: Authors.

${ }^{5}$ We used the monetary threshold computed by the National Institute of Statistics in 2012. Indeed, the annual monetary threshold equals to $869,210.3 \mathrm{CDF}$ for urban area and to $579,248.5 \mathrm{CDF}$ for rural area. We divided both by 12 to get the monthly threshold for the worker's income in the survey was reported per month. If the worker's income is less than 72,434.19 CDF and 48,270.71 CDF in urban area and rural area respectively, then the employee is poor and otherwise, he is non-poor. 
-Pr: Promotion;

-Tr: Training;

-Wh: worked hours;

-Jb: Job protection;

-Es: Employer's support.

\section{Results of Study}

As Table 1 suggests, the labour market in DR Congo is dominated by female (53.64\%) and their counterpart comes after (46.36\%). The distribution of workers in terms of place of residence is almost the same, $50.87 \%$ of employees work in rural area against $49.13 \%$ in urban area. The employees are still young because the median age is comprised between 35 and 39 years. Regarding the education attainment, most of employees have not attended University (41.14\%), apart from $6.10 \%$, after being granted the diploma of secondary school. From that, we can draw a conclusion that the congolese's workers are less skilled. As we get a close look to the job quality information, it is not surprising to highlight that most of employees have not been promoted (99.24\%), neither attended any training program supported by their employers $(88.35 \%)$ given their education background. Among those working in informal (85.44\%), the majority spend less than $45 \mathrm{~h}$ in work $(80.56 \%)$. This fact sustains the evidence that the informal sector does not comply with the labour market regulations. The main feature of informal job is the lack (or lowest) of job protection, which means, no existence of union membership (92.13\%), no signed a work contract $(97.8 \%)$, no paid leave $(99.42 \%)$, no paid health care $(99.51 \%)$ and no social contribution (99.32\%). Furthermore, those employees (informal) do not receive the support from their employers (99.61\%). On the opposite, the employees working in formal sector are covered by the high job security which is mainly featured by a signed work contract $(64.57 \%)$ and an union membership (37.87\%).

Consequently, most of employees are poor (84.53\%) and their income stand at 20,216.47 CDF and 13,582.15 CDF at the mean and median level respectively ${ }^{6}$. Only, $15.67 \%$ of congolese workers are non-poors and gain 164,472.3 CDF and 104,362.9 CDF at the mean and median level respectively.

In Table 2 and Figure $2^{7}$, we computed the weight of the Job security components. Following its dimensions, signed a work contract account for $40 \%$ and the paid leave come after with $20 \%$. The other share the remaining, that is, the paid health care (20\%), paid leave (14\%) and social contribution (10\%).

We then constructed the Job security index-with acceptable internal consistency for Cronbanch's alpha equals to 0.721-as the weighted average of its dimension as follows:

${ }^{6}$ To convert those values in USD dollars, on can use the 2012 exchange rate where $\$ 1$ equals to 919 CDF.

${ }^{7}$ We have normalized the weights of Job security components to sum up to unity following OECD (2008: p. 90). 
Table 1. Descriptive statistics.

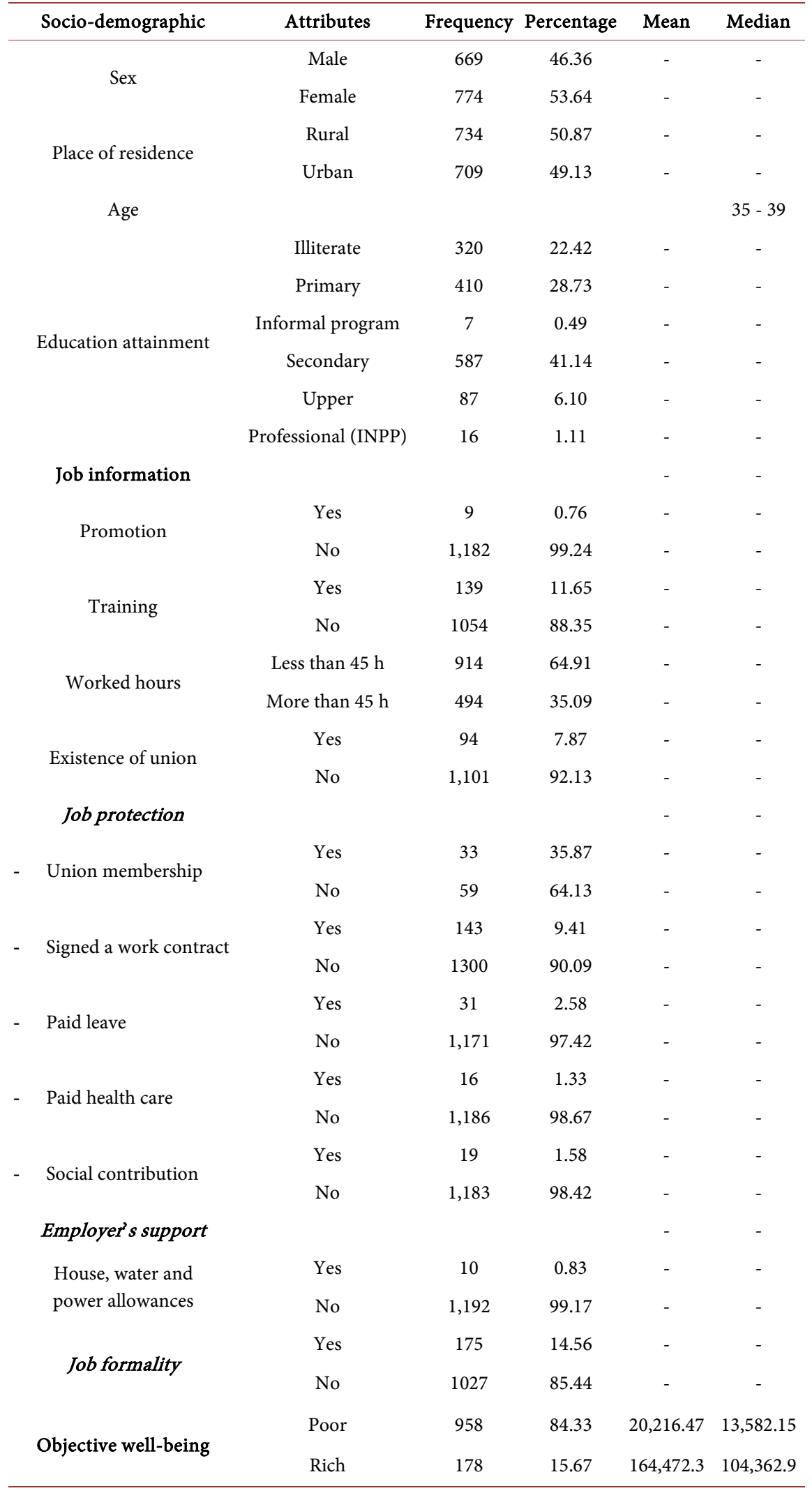

Source: Authors' own calculations based on 2012 survey 1-2-3. 


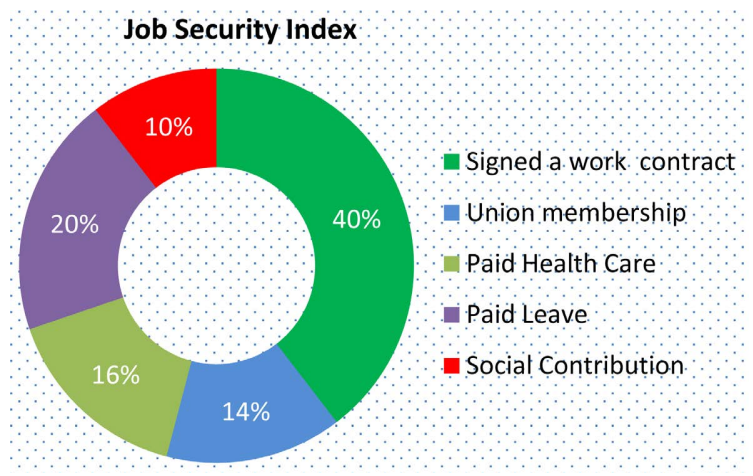

Figure 2. Contribution of job security components (\%). Source: Authors' own calculations based on 2012 survey 1-2-3.

Table 2. Job security index.

\begin{tabular}{cc}
\hline Components & Job Security \\
\hline Signed work contract & 0.684 \\
Union membership & 0.414 \\
Paid Health Care & 0.431 \\
Paid Leave & 0.483 \\
Social Contribution & 0.352 \\
Cronbach's Alpha & 0.721 \\
Eigenvalue & 2.364 \\
Inertia & 0.473 \\
\hline
\end{tabular}

Source: Authors' own calculations based on 2012 survey 1-2-3.

$$
\mathrm{JS}=0.10 * \mathrm{Sw}+0.14 * \mathrm{P} 1+0.16 * \mathrm{Ph}+0.20 * \mathrm{P} 1+0.40 * \mathrm{Sw}
$$

Afterwards, we discretized this index: above the mean, its value reflects the high job security and otherwise, the low job security. Behind that transformation, our main concern was to construct the Job quality index, of which the Job security is one of the component. Based on that, all variables are nominal, we applied again the Multiple Correspondance Analysis not for the sub-index of the Job quality anymore but for all its components.

As a result, the Employer's support, worked hours and promotion are visibly the less significant components due to their weights which do not exceed 0.30 (Column 1, Table 3). This is highly consistent as we refer to the descriptive statistics. In accordance with literature, those factors are likely to be removed. The removal of those three components has improved both the internal consistency and the total explained variance passing from 0.603 to 0.721 and from $33.5 \%$ to $64.7 \%$ respectively.

As for contribution, Table 2 (column 2) and Figure 3, depict that the job security accounts for $46 \%$ and appear then the most important components of the job quality, followed by existence of union (39\%) and training (15\%). 


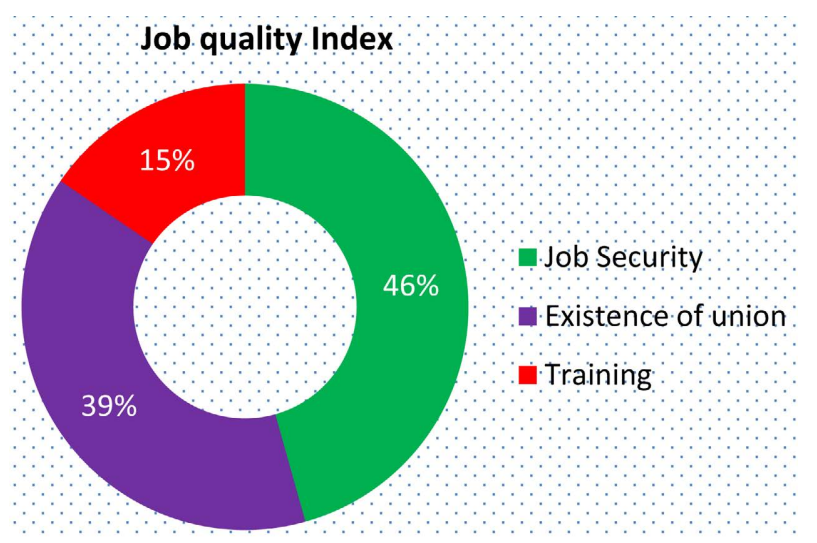

Figure 3. Contribution of job quality components (\%). Source: Author's own calculations based on 2012 survey 1-2-3.

Table 3. Job quality index (Jqi).

\begin{tabular}{ccc}
\hline Components & Job Quality & Job Quality $^{* *}$ \\
\hline Job Security & 0.741 & 0.782 \\
Existence of union & 0.687 & 0.711 \\
Training & 0.455 & 0.448 \\
Employer's support & 0.056 & \\
Worked hours & 0.039 & \\
Promotion & 0.031 & \\
Cronbach's Alpha & 0.603 & 0.727 \\
Eigenvalue & 2.009 & 1.941 \\
Inertia & 0.335 & 0.647 \\
\hline
\end{tabular}

Source: Authors' own calculations based on 2012 survey 1-2-3. **: After removing the Employer's support, Worked hours and Promotion due to their lowest contributions to the Job quality index, i.e., less than 0.30 .

So, the job quality index is constructed as the weighted average of its all components except those that were removed:

$$
\text { Jqi }=0.15 * \operatorname{Tr}+0.39 * \mathrm{Eu}+0.46 * \mathrm{Js}
$$

Following Cassar (2010), the econometric model can be thus rewritten as follows:

$$
\mathrm{OWB}=a_{0}+a_{1} \mathrm{Jqi}+\mathrm{AX}+\mu
$$

With: OWB: Objective well-being $=\left\{\begin{array}{l}0 \text { if the employee is poor } \\ 1 \text { if the employee is non-poor }\end{array}\right.$

$\mathrm{X}$ : Vector of Socio-demographic variables.

Let now assess the job quality effects on the worker's well-being. To do so, we estimated the logit model as described in Equation (4). As suggest Table 4, the effect of job quality is significantly positive on worker's well-being in both cases workers from Informal Sector (column 1) and all workers irrespectively of 
Table 4. Estimation of econometric model.

\begin{tabular}{cccc}
\hline \multirow{2}{*}{$\begin{array}{c}\text { Dep. Variable: } \\
\text { Well-being }\end{array}$} & $\begin{array}{c}\text { Marginal effects } \\
\text { Informal Sector (model 1) }\end{array}$ & $\begin{array}{c}\text { Workers from } \\
\text { Formal Sector (model 2) }\end{array}$ & $\begin{array}{c}\text { All workers } \\
\text { (model 3) }\end{array}$ \\
\cline { 2 - 4 } & $0.3776^{* *}$ & $-0.0065^{* * * *}$ & $0.1594^{*}$ \\
Job quality index & $(2.41)$ & $(-0.04)$ & $(1.83)$ \\
Education & $0.0249^{* *}$ & $0.0040^{*}$ & $0.0428^{* * *}$ \\
& $(2.32)$ & $(0.08)$ & $(3.94)$ \\
Sex & $-0.1427^{* * *}$ & $0.0943^{* * * *}$ & $-0.1121^{* * *}$ \\
Age & $(-5.04)$ & $(1.09)$ & $(-4.05)$ \\
& $0.0124^{* *}$ & $0.0263^{*}$ & $0.0144^{* * *}$ \\
Age squared & $(2.41)$ & $(1.82)$ & $(3.14)$ \\
& $-0.0001^{* *}$ & $-0.0002^{*}$ & $-0.0001^{* * *}$ \\
Place of Residence & $(-2.23)$ & $(-1.67)$ & $(-2.80)$ \\
Observations & $-0.0136^{* * * *}$ & $0.0463^{* * * *}$ & $-0.0135^{* * * *}$ \\
& $(-0.51)$ & $(0.45)$ & $(-0.49)$ \\
\hline
\end{tabular}

Source: Author's own calculations based on 2012 survey $1-2-3 .{ }^{* * *} p<0.01 ;{ }^{* *} p<0.05 ;{ }^{*} p<0.1 ;{ }^{* * * *} p>0.1$. ( ): refer to the $\mathrm{z}$-values.

their sector (column 3). In the first case, that relation implies the need of controlling and strengthening the job quality in informal sector; for increases in job security index by one unit ${ }^{8}$, the probability that worker's well-being increases is 0.38 . This effect is divided approximately by half when the sample covers the all workers. On contrary, we did not find the significant relationship between the job quality and the worker's well-being in formal sector. This finding can be explained by the job quality level which is already high in formal sector compared to informal sector. For all workers, the effect of the job quality on worker's well-being in informal sector is dominant to that in formal sector, which explains the significant impact of the job quality, by and large. The level of education impacts positively and significantly the worker's well-being regardless of the estimated model. The probability of worker's well-being decreases with the age, the more the workers are young, the more their well-being increases and inversely. The worker's well-being depends on the sex (except for the model 2) and remains unaffected by the place of residence.

In order to check the validity of our model, we conducted the sensitivity analysis following the works of Payne et al. (2015) ${ }^{9}$. Prior to that, we assessed the performance of our model (Table 5 and Table 6). In the last case i.e. model 3, the overall rate of correct classification is estimated to be $80.36 \%$, with $81.03 \%$ of predicting the poor workers group and only $33.33 \%$ of predicting the non-poor workers group. Regarding both the model 1 and model 2, the estimated overall rates of correct classification are $84.93 \%$ and $63.46 \%$ respectively. ${ }^{8}$ Scaled from 0 to 10 where 0 expresses very bad quality and 10 the highest quality.

${ }^{9}$ Thanks to the anonymous reviewers for their helpful comments. 
Table 5. Model performance.

\begin{tabular}{cccc}
\hline & Model 1 & Model 2 & Model 3 \\
\hline Over all rate classification & $84.93 \%$ & $63.46 \%$ & $80.36 \%$ \\
Positive predicted value (non-poor workers) & $60 \%$ & $62.50 \%$ & 33.33 \\
Negative predicted value (poor workers) & $85.10 \%$ & $63.51 \%$ & $81.03 \%$ \\
\hline
\end{tabular}

Source: Authors' own calculation based on the 2012 survey 1-2-3.

Table 6. Sensitivity analysis.

\begin{tabular}{|c|c|c|c|c|c|c|c|c|c|}
\hline & \multirow{2}{*}{\multicolumn{3}{|c|}{$\begin{array}{c}\text { Initial model } \\
\text { Estimated poverty's } \\
\text { threshold by INS }\end{array}$}} & \multicolumn{6}{|c|}{ Re-specified Model } \\
\hline & & & & & $\begin{array}{c}\text { Minimum } \\
\text { wage }\end{array}$ & & $\begin{array}{l}\mathrm{W} \\
\text { pove }\end{array}$ & $\begin{array}{l}\text { orld ban } \\
\text { erty thres }\end{array}$ & $\begin{array}{l}\text { k's } \\
\text { hold }\end{array}$ \\
\hline & Model 1 & Model 2 & Model 3 & Model 1 & 1 Model 2 & Model 3 & Model 1 & Model 2 & Model 3 \\
\hline $\begin{array}{l}\text { Area under } \\
\text { ROC Curve }\end{array}$ & 0.74 & 0.57 & 0.72 & 0.75 & 0.71 & 0.75 & 0.74 & 0.68 & 0.76 \\
\hline
\end{tabular}

Source: Authors' own calculation based on the 2012 survey 1-2-3.

Based on predicting power, out of $84.93 \%$ of the estimated correct classification in model $1,85.10 \%$ of the poor workers group is well predicted against $60 \%$ of the non-poor. Within the model 2 , out of $63.46 \%$ of the estimated correct classification, the well predicted groups represent $63.51 \%$ for the poor workers and $62.50 \%$ for the non-poor workers. Our model is then suitable for predictive analysis.

Furthermore, we assessed its sensitivity. We re-specified our model using the world bank's threshold poverty of \$1.90 PPA per day and the 2003 actualized minimum wage of 2.28 per day in accordance with the Institut National de Statistique's (INS) report survey 1-2-3 of the $2012^{10}$. The well-being (dependent variable) is afterwards re-generated for each fixed threshold to separate poor workers group from non-poor. We applied then the ROC Curve. Table 6 summarizes the results of sensitivity analysis. The sensitivity analysis to assess performance of the model using the estimated poverty's threshold by INS, the minimum wage and the word bank's poverty threshold, demonstrated clearly that the model's discrimination ability, which means, separating poor workers group from non-poor is well maintained.

\section{Conclusion}

Approaching labour market in the context of segmentation, this study assessed the impact of job quality on worker's well-being. Using the first stage of the 2012 national survey data 1-2-3, preliminary results revealed that among $1443 \mathrm{em}$ ployees, $85.44 \%$ were working in informal sector whereas $14.56 \%$ in formal sector. Given its multidimensionnal characteristics, the job quality was measured by ${ }^{10} \mathrm{We}$ converted both thresholds into Congolese Franc (CDF) using the 2012 exchange rate $(1 \$=$ $919 \mathrm{CDF}$ ) and expressed them in month by multiplying by 30 . 
six components such as job security, existence of union, training, employer's support, worked hours and promotion. In terms of contribution of each dimension, the Multiple Component Analysis was applied and the finding has to lead us to select the three first components with $46 \%, 39 \%$ and $15 \%$ of contribution respectively on constructing the job quality index. On the other side, the well-being was measured by worker's income and two classes-non-poor employees and poor employees-were created using the 2012 monetary threshold according to the place of residence.

Based on that the dependent variable (well-being) is binary, we estimated the logit model. Our results revealed that the effect of job quality was significantly positive on worker's well-being in both cases workers from Informal Sector and all workers irrespectively of their sector. In formal sector, the evidence of the significant impact of job quality was statistically rejected. The main explanation of this finding can be imputed to the job quality level which was already high in formal sector compared to informal sector. Furthermore, for all workers, this result was a consequence of the dominant effect of the job quality on worker's well-being in informal sector on that in formal sector.

In view of above findings, there is a need of controlling and strengthening the job quality in informal sector for an increase in job security index by one unit, the probability that worker's well-being increases is 0.38 .

Taking into account the dualism sector-which is the common stylized feature in Africa's labour market and more specifically in DR Congo-in analyzing the effect of job quality on worker's well-being is the main contribution of this study in this area. In our modest knowledge, there is no yet kind of this study neither in Africa nor in DR Congo. As a limit, the well-being was measured on one dimension, that is, the worker's income. Since Sen's works, it is suitable to combine both monetary and non-monetary approach in capturing the well-being. Further researchers may bring more knowledge on that approach. Furthermore, this research was not able to address selection and causality issues adequately as the study can only use one wave of the survey. Those issues can successfully be handled with the panel data i.e. the same individuals or households are repeatedly observed over the time.

\section{Conflicts of Interest}

The authors declare no conflicts of interest regarding the publication of this paper.

\section{References}

Ariza-Montes, A., Giorgi, G., Hernández-Perlines, F., \& Fiz-Perez, J. (2018). Decent Work as a Necessary Condition for Sustainable Well-Being. A Tale of Pi(i)gs and Farmers. Sustainability, 11, Article No. 1051, 19 p. https://doi.org/10.3390/su11041051

Bryson, A., Green, F., Bridges, S., \& Craig, R. (2012). Well-Being, Health and Work (36 p). Discussion Paper No. 387, National Institute of Economic and Social Research. 
Cassar, L. (2010). Quality of Employment and Job Satisfaction: Evidence from Chile (19 p). Research Paper: 17a, Oxford Poverty and Human Development Initiaves.

Chen, W.-H., \& Hou, F. (2018). The Effect of Unemployment on Life Satisfaction: A Cross-National Comparison between Canada, Germany, the United Kingdom and the United States (28 p). Analytical Studies Branch Research Paper Series, Social Analysis and Modelling Division, Statistics Canada.

Clark, A. (2005). Your Money or Your Life: Changing Job Quality in OECD Countries. British Journal of Industrial Relations, 43, 377-400. https://doi.org/10.1111/j.1467-8543.2005.00361.x

Clark, A. (2010). Work, Jobs, Well-Being across the Millennium. In E. Diener, J. F Helliwell, \& D. Kahneman (Eds.), International Differences in Well-Being, Oxford University Press. https://doi.org/10.1093/acprof:oso/9780199732739.003.0014

Doeringer, P. B., \& Piore, M. J. (1970). Internal Labor Markets and Manpower Adjustment. New York: DC Health and Company.

Esenaliev, D., \& Ferguson, N. (2019). The Impact of Job Quality on Well-being: Evidence from Kyrgyzstan. Social Indicators Research, 144, 337-378.

https://doi.org/10.1007/s11205-018-1998-9

Grunberg, L., Moore, S., Greenberg, E., \& Sikora, P. (2008). The Changing Workplace and Its Effects. The Journal of Applied Behavioral Science, 44, 215-235. https://doi.org/10.1177/0021886307312771

Guzi, M., \& de Pedraza García, P. (2015). A Web Survey Analysis of Subjective Well-Being. International Journal of Manpower, 36, 48-67. https://doi.org/10.1108/IJM-12-2014-0237

Kabote, S. (2017). Revisiting Subjective Wellbeing to Stimulate Empirical Research in Sub-Saharan Africa. Socials Sciences, 6, 28-34. https://doi.org/10.11648/j.ss.20170601.15

Lugo, M. (2007). Employment: A Proposal for Internationnally Comparable Indicators. Oxford Development Studies, 35, 361-368. https://doi.org/10.1080/13600810701701889

Mafini, C. (2014). The Relationship between Job Satisfaction and Life Satisfaction: Empirical Evidence from Logistics Practitioners in a South African Steel-Making Company. International Business \& Economics Research Journal, 13, 453-462. https://doi.org/10.19030/iber.v13i3.8585

Mafini, C., \& Dlodlo, N. (2014). The Relation between Extrinsic Motivation, Job Satisfaction and Life Satisfaction among Employees in Public Organization. SA Journal of Industrial Psychology, 40, Article No. a1166, 13 p.

https://doi.org/10.4102/sajip.v40i1.1166

Moroc, A., \& Bărnuțiu, O. (2019). Job Quality, Innovation and Employment-A Structural Equation Modeling on Regional Level. International Journal of Innovation and Economic Development, 5, 54-65. https://doi.org/10.18775/ijied.1849-7551-7020.2015.51.2005

Muñoz de Bustillo, R., Fernández-Macías, E., Antón, J.-I., \& Esteve, F. (2011). Measuring More than Money: The Social Economics of Job Quality. Edward Elgar. https://doi.org/10.4337/9781849805919

Nichols, A., Mitchell, J., \& Lindner, S. (2013). Consequences of Long-Term Unemployment. Urban Institute.

OECD (Organisation for Economic Co-Operation and Development) (2008). Handbook on Constructing Composite Indicators: Methodolgy and User Guide (162 p). OECD Publishing. https://doi.org/10.1787/9789264043466-en 
OECD (Organisation for Economic Co-operation and Development) (2013). How's Life? 2013: Measuring Well-Being (216 p). OECD Publishing. https://doi.org/10.1787/9789264201392-en

Osei-Bonsu, N. (2014). The Impact of Change Management on Job Satisfaction on Employee's in Ghana's Banking Sector. Problems of Management in the 21st Century, 9, 140-149. https://doi.org/10.33225/pmc/14.09.140

Payne, B. A., Groen, H., Vivian Ukah, U., Mark Ansermino, J., Bhutta, Z., Grobman, W. et al. (2015). Development and Internal Validation of a Multivariable Model to Predict Perinatal Death in Pregnancy Hypertension. Pregnancy Hypertension, 5, 315-321. https://doi.org/10.1016/j.preghy.2015.08.006

Pereira, S., Santos, D., \& Pais, L. (2019). Empirical Research on Decent Work: A Literature Review. Sandinavian Journal of Work and Organizational Psyhology, 4, 1-15. https://doi.org/10.16993/sjwop.53

Pharr, J. R., Moonie, S., \& Bungum, T. J. (2012). The Impact of Unemployment on Mental and Physical Health, Access to Health Care and Health Risk Behaviors. International Scholarly Research Notices, 2012, Article ID: 483432. https://doi.org/10.5402/2012/483432

Sivapragasam, P., \& Raya, R. (2014). Exploring the Link between Job Quality and the Employee Well-being: An Empirical Study. Asia-Pacific Journal of Management Research and Innovation, 10, 267-277. https://doi.org/10.1177/2319510X14553697

Wanberg, R. (2012). The Individual Experience of Unemployment. Annual Review of Psychology, 63, 369-396. https://doi.org/10.1146/annurev-psych-120710-100500

Warhurst, C., Wright, S., \& Lyonette, C. (2017). Understanding and Measuring Job Quality (42 p). Research Report, CIPD (Chartered Institute of Personnel and Development).

Western, M., \& Tomaszewski, W. (2016). Subjective Wellbeing, Objective Wellbeing and Inequality in Australia. PLOS ONE, 11, e0163345.

https://doi.org/10.1371/journal.pone.0163345 